This item was submitted to Loughborough's Research Repository by the author.

Items in Figshare are protected by copyright, with all rights reserved, unless otherwise indicated.

\title{
Quick win or slow burn? Modelling UK HE CAA uptake
}

PLEASE CITE THE PUBLISHED VERSION

PUBLISHER

(c) Loughborough University

VERSION

AM (Accepted Manuscript)

LICENCE

CC BY-NC-ND 4.0

REPOSITORY RECORD

Warburton, Bill. 2019. "Quick Win or Slow Burn? Modelling UK HE CAA Uptake". figshare. https://hdl.handle.net/2134/4444. 
This item was submitted to Loughborough's Institutional Repository (https://dspace.lboro.ac.uk/) by the author and is made available under the following Creative Commons Licence conditions.

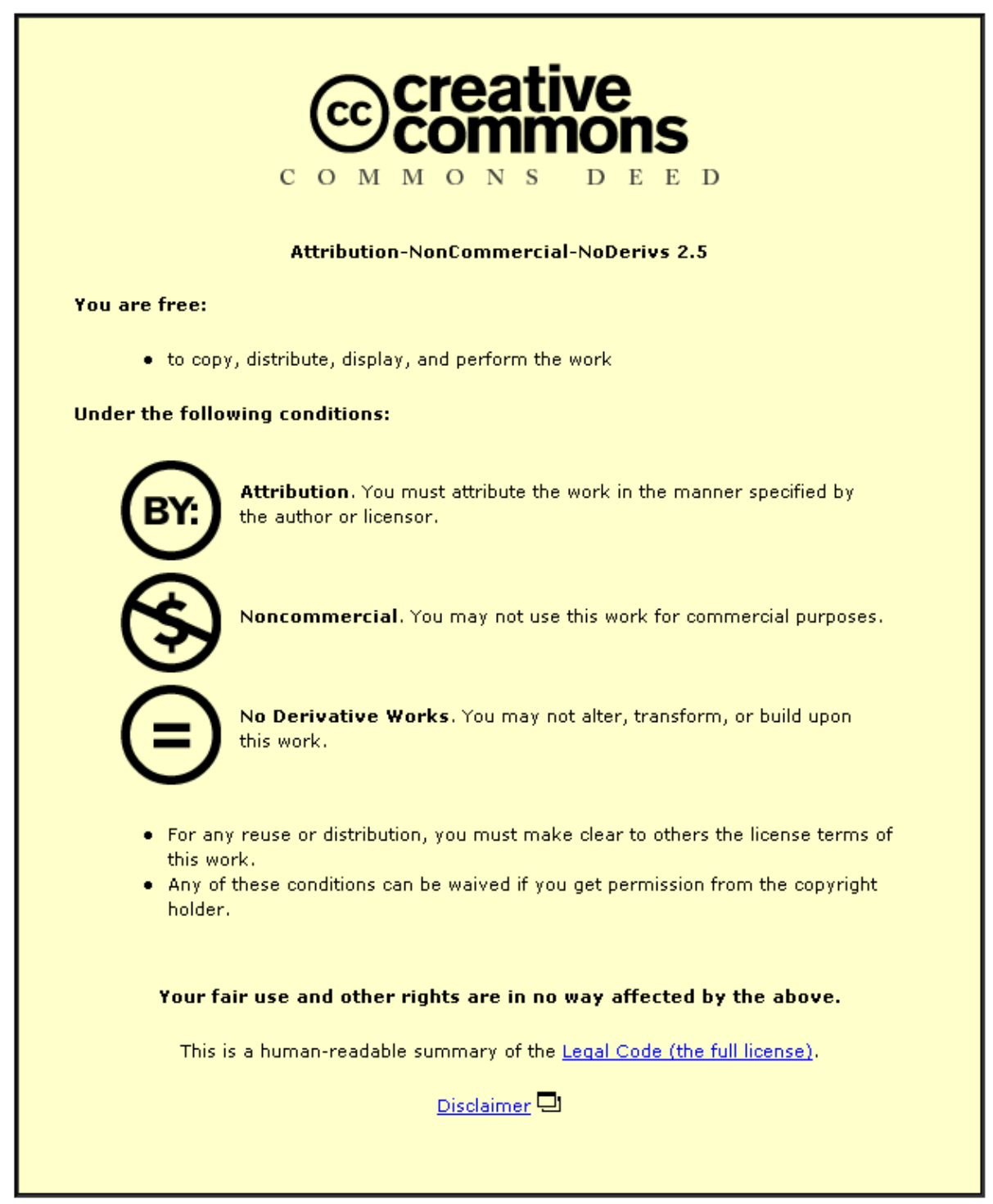

For the full text of this licence, please go to: http://creativecommons.org/licenses/by-nc-nd/2.5/ 


\section{QUICK WIN OR SLOW BURN? MODELLING UK HE CAA UPTAKE}

Bill Warburton 



\title{
Quick Win or Slow Burn? Modelling UK HE CAA Uptake
}

\author{
Bill Warburton \\ University of Southampton \\ W.I.Warburton@soton.ac.uk
}

\begin{abstract}
The uptake of CAA in UK higher education (HE) on a large scale lags behind the expectations of CAA specialists. A research project was undertaken with the aim of discovering and addressing the underlying reasons for this. The research was conducted according to Strauss and Corbin's (1998) prescription for grounded theory (GT) research. During three years a 200000 word dataset was compiled from a national survey by questionnaire and interview with tutors, learning technologists, managers and QA staff. This article describes the dual-path theory of CAA uptake that emerged from an analysis of this dataset. Ways in which dual-path theory might be used to understand and improve CAA uptake are proposed.
\end{abstract}

\section{Quick Wins?}

Time pressures on tutors across the sector are well documented (Bull, 1999; Gibbs, Habeshaw and Yorke, 2000) and are often compounded by increasing demand for research output that will raise their profile in the next research assessment exercise (RAE). This promotes a utilitarian approach to assessment activities which prizes quick returns above pedagogic gains or longer term considerations such as an expected reduction in assessment load once a large item bank has been built. CAA was widely acknowledged to offer the potential of productivity gains in terms of more efficient authoring, publication, delivery, marking and reporting, which was summed up by some respondents as an effective reduction in paperwork.

However it also emerged that where unsupported tutors sought these 'quick wins' without investing in preparative activities such as seeking the advice of experienced colleagues or setting up formative exercises and practice quizzes, the degree of risk taken on all at once could be so significant that colleagues were discouraged from using CAA themselves. This effect was prominent in extreme cases such as student data loss during an invigilated examination:

... when the email came round about the [CAA] disaster... some of those colleagues... just went non-linear... how can we possibly have... taken on something which under the most fundamentally obvious things that it had to work under, it fails at the first hurdle? (Tutor Am05M007) 
The effect was less pronounced where the unfavourable outcome was limited to unplanned expenditure of time and effort, for example to recover data or reassure students. Failure to think through the implications of using CAA can have serious implications:

... a CAA had been taken and the results had been distributed to [an inexperienced] tutor, the tutor had given them to someone... who... sent them to an external [examiner], including a detailed breakdown of the item analysis of the assessment, which the tutor didn't understand and hadn't intended to go. So the external [examiner] looked at all this and said 'thank you very much, your test appears to be invalid'. (Learning technologist LtO3M001)

Unintended outcomes of this kind threaten the CAA user's credibility. The increased risk incurred by productivity-driven approaches to CAA applications and the braking effect they have on uptake by colleagues represents an extreme case and is shown in the upper half of the paradigm model (Figure 1). It should be noted that this opening of the assessment process to public scrutiny could be regarded as an unintended consequence of CAA which is seldom included in risk registers. Until recently assessment feedback was rarely given, not least because the examination system was ill equipped to provide it. Therefore participants didn't expect feedback and there was no possibility of a debate about academic standards. Now people know it can be done so they take it for granted, not only for formative and diagnostic use but also for summative assessment as well.

\section{Slow Burn?}

Conversely, where tutors aimed primarily for pedagogical improvements they incurred much less risk and the resultant trajectories were characterised by routine use of small scale quizzes with an initial emphasis on low stakes testing such as formative and diagnostic applications. This sometimes progressed towards higher stakes testing on a larger scale.

A staged approach was encouraged by learning technologists who recognised the value for tutors of learning to use complex CAA tools in less critical applications. High stakes applications such as examinations were seen by learning technologists as the final goal of CAA trajectories rather than a starting point. Experienced CAA using tutors agreed.

Staged lower risk trajectories generally produced modest productivity gains and consequently diffusion was steady rather than spectacular. Where tutors emulated this approach, they appeared to do so because they perceived a structured, methodical pattern of practice which would protect their investment in assessment materials and which might yield sustainable if modest productivity gains in the medium to long term.

The reduced risk incurred by pedagogically-driven attitudes to CAA use and the accelerating effect this has on uptake by colleagues is shown in the lower half of the model (Figure 1). 


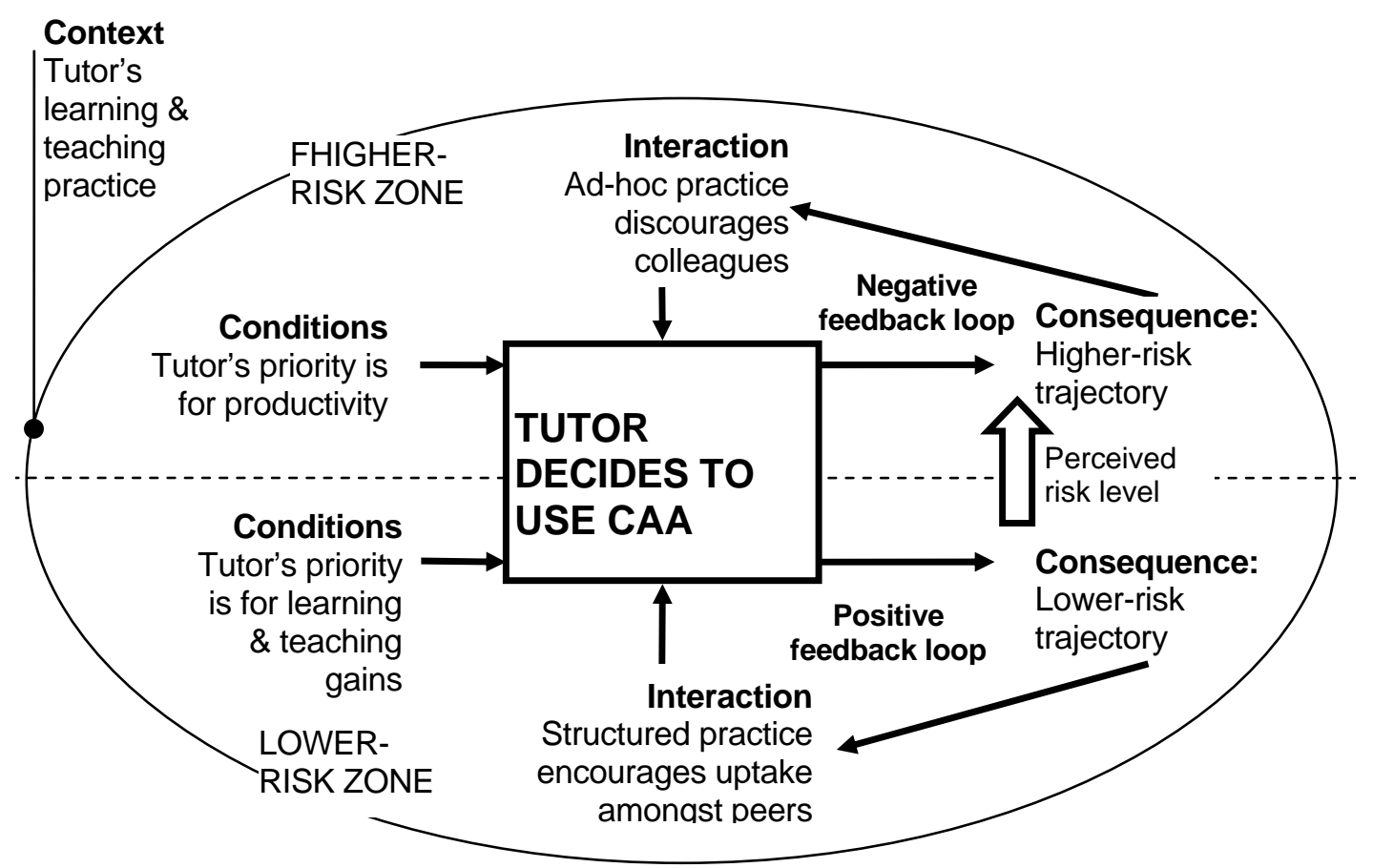

Figure 1. Core dual-path theory of uptake

Internal risk mitigation

In cases where tutors are already experienced, or are supported by experienced colleagues and learning technologists, this constituted a degree of risk mitigation that could shift what would otherwise have been risky CAA practice into a lower risk trajectory. This mitigating action could be taken by CAA users themselves as 'internal' risk mitigation or by learning technologists on their behalf as 'external' risk mitigation.

\section{External risk mitigation}

In other cases risk mitigation was performed by learning technologists, who were keenly aware of the underlying fragility of CAA systems ('... the least little thing missed can knock the whole system out' - Learning technologist LtO3F002). An overarching aim of these activities was to make CAA systems easier to use, thus reducing the scope for things to go wrong.

A physical aspect of the risk mitigation that learning technologists undertook was to ensure that the integrity of CAA systems, including associated infrastructures, was beyond reproach. These physical measures were sometimes triggered by problems that occurred during high-stakes use where risky practice had exposed underlying weaknesses such as scalability issues:

... this is its first semester of use and the take-up was so high - so much higher that it led to fairly spectacular problems with it, which... we've now sorted by tuning the system (Learning technologist LtO5M002) 
A cultural aspect of risk mitigation by learning technologists was to ensure that appropriate CAA procedures existed and were observed by tutors. CAA policies and procedures were easily overlooked:

... we had an incident this year where one of the lecturers... overlooked a procedure which compromised the exam just beforehand and now they have gone off using the system as a result of that oversight. So even though the procedures were in place and he neglected to do one aspect, it has tarnished his view on [CAA]. (Learning technologist LtN2M003)

Risk mitigating measures of both kinds were taken by learning technologists in a recursive fashion which resulted in a progressively closer fit of mitigation to practice (Harwood and Warburton, 2004).

\section{Strategic Support}

The role of strategic support in legitimating CAA was particularly evident in new universities where centralised organisational structures facilitated the promulgation of CAA policies and procedures:

... ultimately we have got one [group of] staff who... filter down all the teaching practices [and] they decide what should [happen] and... it gets validated by them: quality procedures and everything... then things come down from the top and CAA practices are imbedded... (Learning technologist LtN2M003)

This is shown as institutional validation of existing good practice and has the direct consequence of increasing uptake by strengthening the remit of the procedural measures put in place by learning technologists. It has the indirect consequence (shown as a dashed line) of increasing uptake by demonstrating the institution's commitment to CAA as a valid tool in the teaching and learning toolkit. The other way in which institutions could drive CAA uptake was by providing a secure funding and thereby further validating CAA. This increases uptake by strengthening the physical infrastructure and, by virtue of committing real resources, has the indirect consequence of increasing uptake by demonstrating the institution's commitment to CAA 


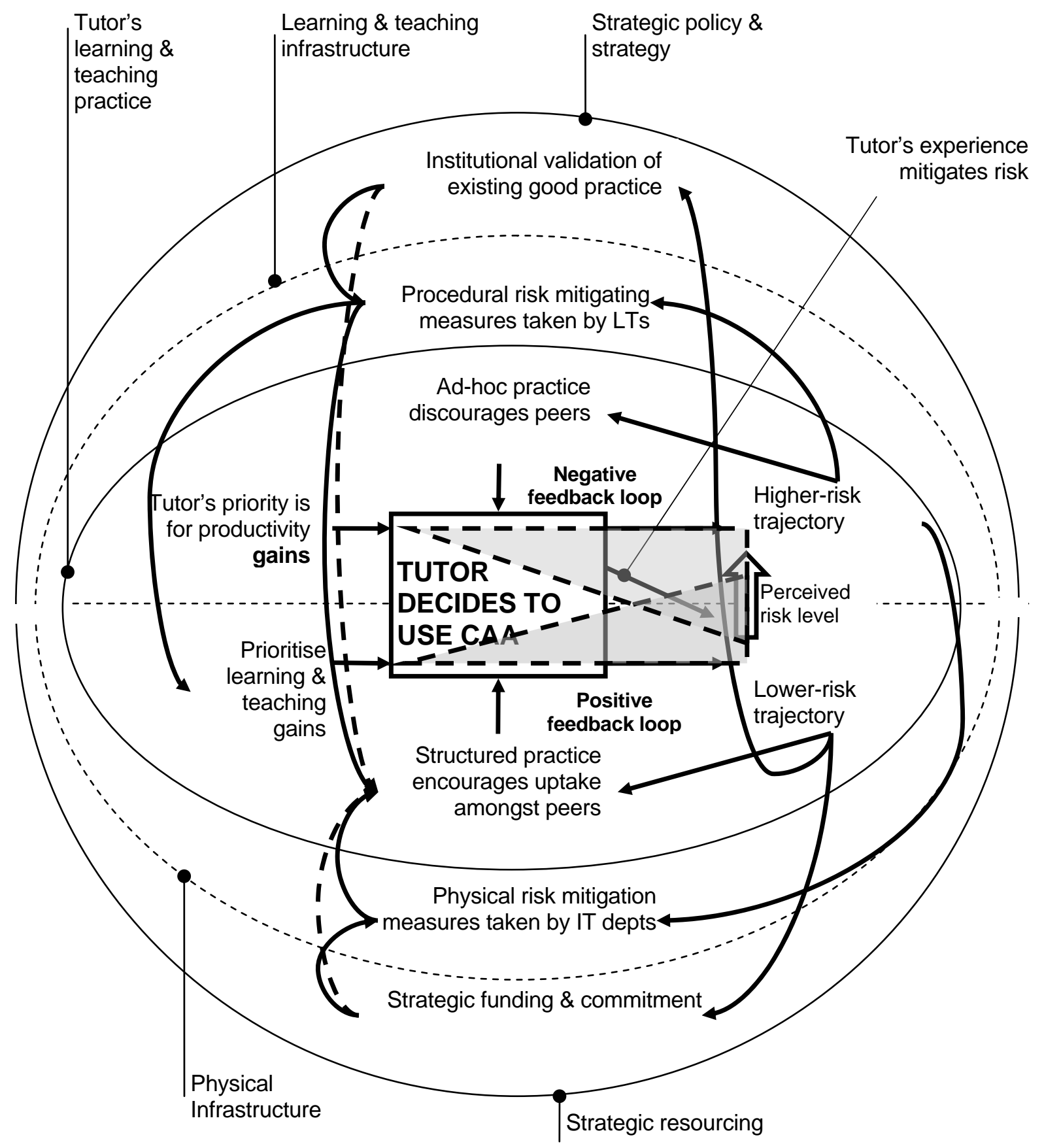

Figure 2- Enhanced dual-path theory showing the influence of strategic support on risk mitigation

\section{The Concentric Shell Model of Uptake}

Populating the enhanced dual-path theory with drivers and obstacles identified in specific institutions results in a concentric shell model of uptake which can be used to identify action for optimal uptake (Figure 3). 


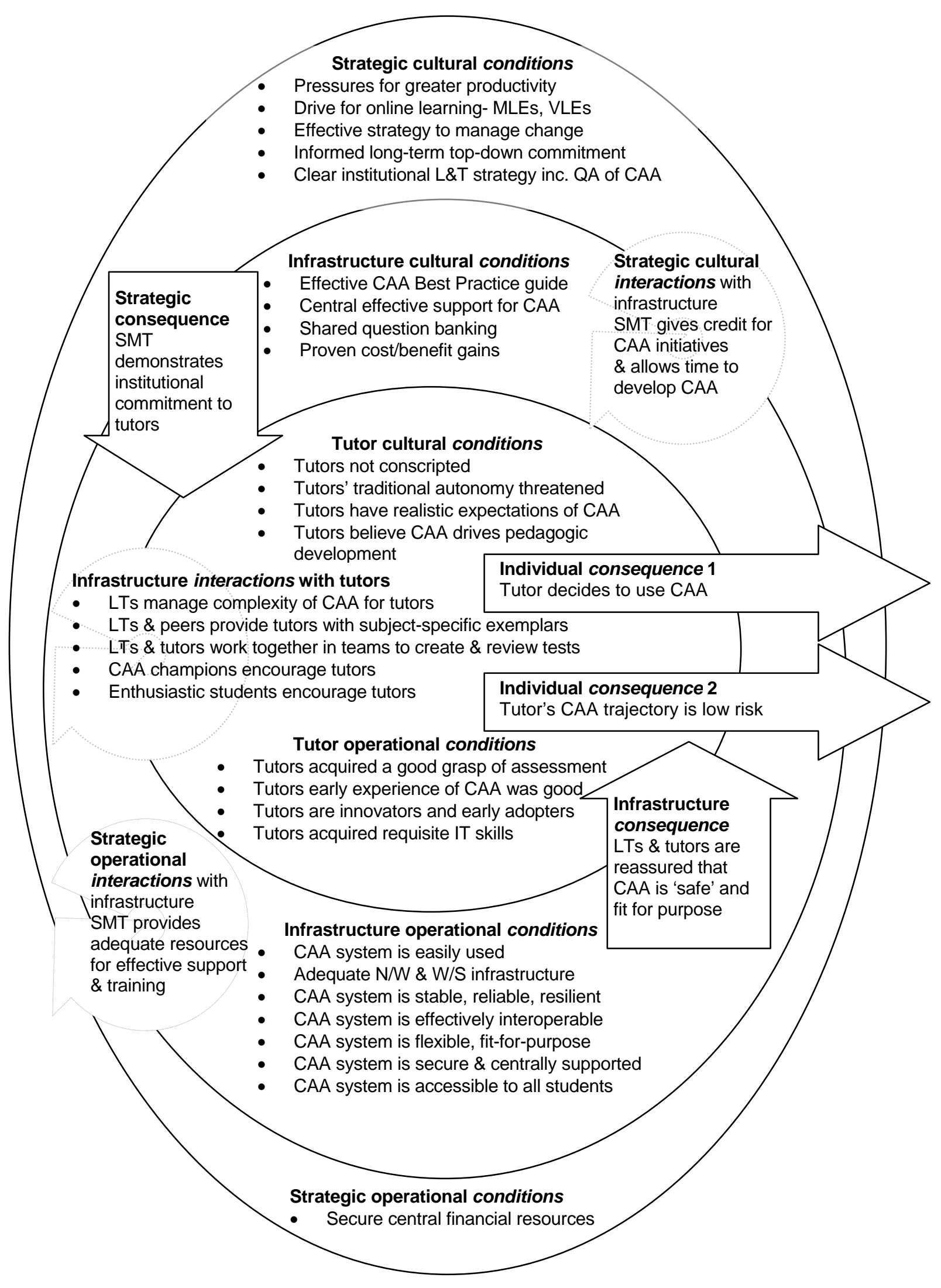

Figure 3- Concentric shell model of CAA uptake showing known drivers 


\section{Tutor Trajectories}

The pattern of CAA uptake over time at the level of individual tutors - their 'trajectory' - is the fundamental unit which, on the micro scale, underlies institutional uptake on the macro level. A tutor's CAA trajectory differs critically from otherwise similar patterns of technology uptake such as VLE use in that a significant element of risk attends technology-based assessment activities, particularly in credit-bearing assessment.

Individual CAA trajectories can be broadly characterised as high or low risk according to the fashion in which tutors progress towards high stakes assessment. Where uptake proceeds in a planned sequential fashion from testing through formative to low and then high stakes summative testing, small increments of risk are incurred in each step which results typically in a linear low risk trajectory. Where uptake proceeds directly to summative use, large increments of risk may be incurred at once which results typically in a non-linear high risk trajectory. The biggest influences on tutor trajectories were their motives for using CAA. Where the aim was primarily to secure productivity gains the consequence was an ad hoc style of use that resulted in high risk trajectories. Where the aim was primarily to improve learning and teaching practice the consequence was a sustained progression through the different stages of CAA use that resulted in lower risk trajectories (Figure 4).

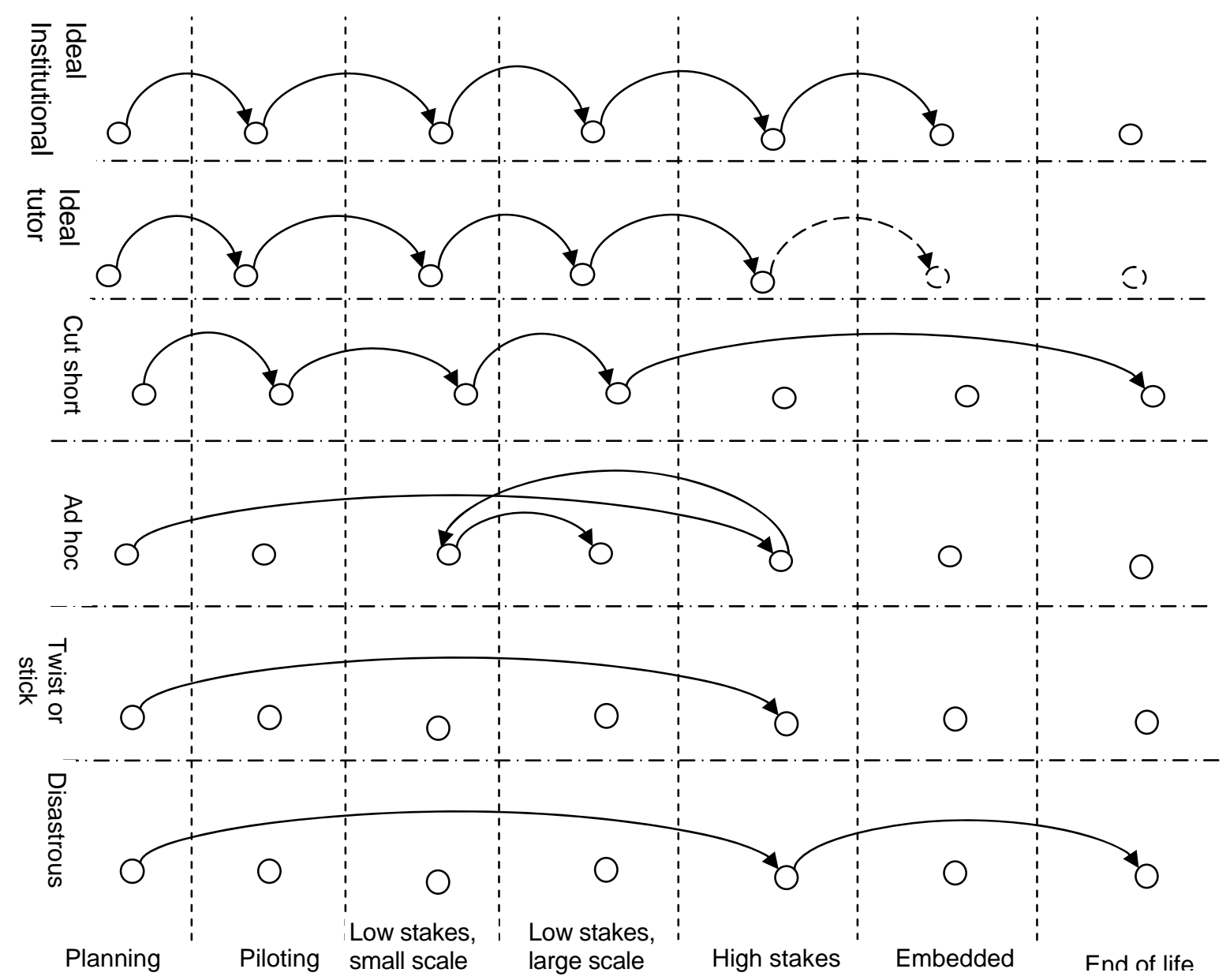

Figure 4- Typical trajectories 


\section{Principle Mechanisms Driving CAA Uptake}

The principle mechanisms appeared to be sevenfold. They are described in ascending order of scale using the concentric cylinder model of uptake (Figure 5).

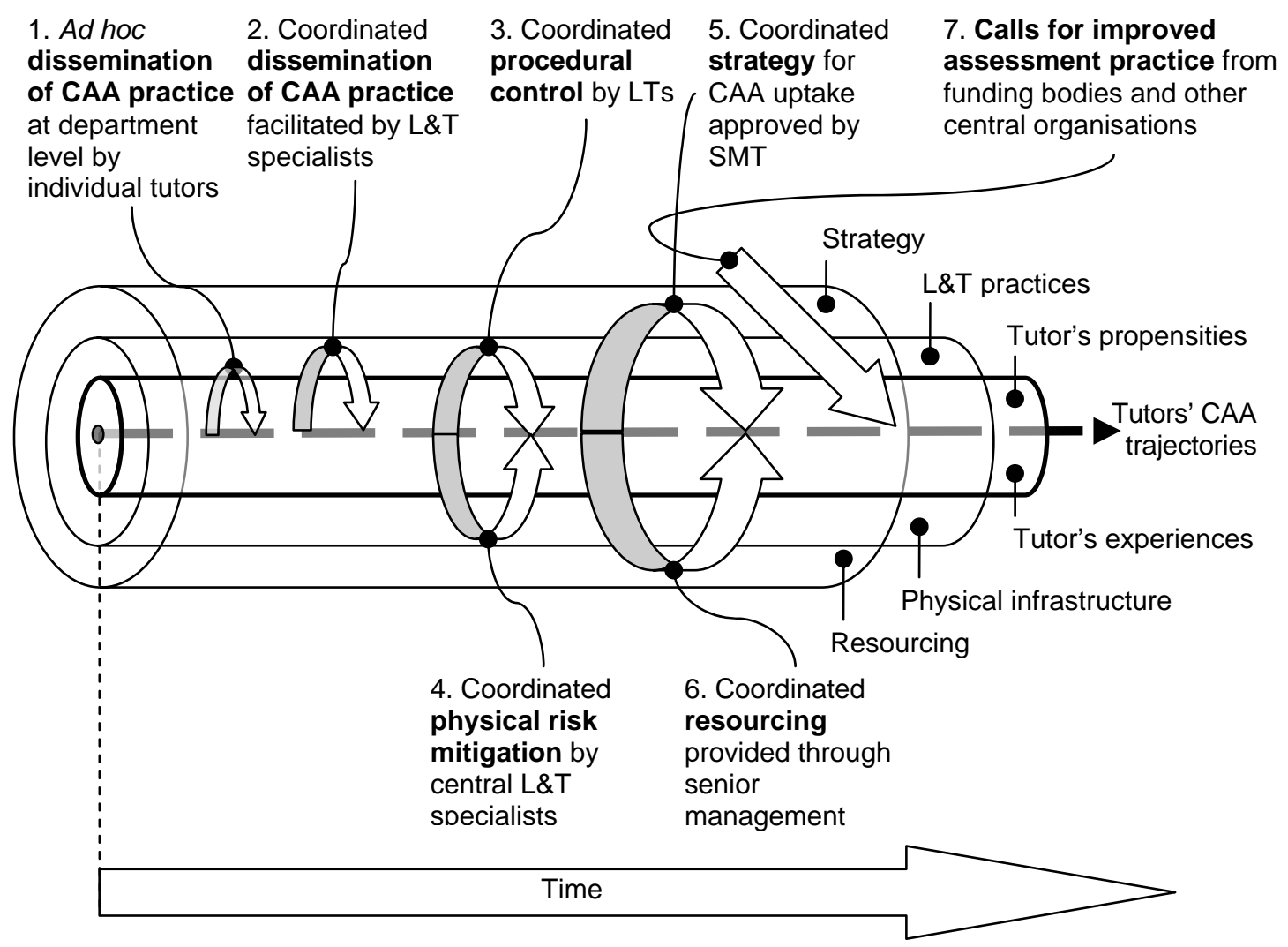

Figure 5 Concentric cylinder model of principle mechanisms driving CAA uptake

It was noted that these mechanisms incur greater latency as they reach higher into the infrastructural and strategic parts of the institution.

\section{Ad hoc dissemination of CAA practice at department level}

The simplest and most direct form of diffusion is unaided 'word of mouth' dissemination among individual tutors who work together as colleagues. This is recognised by learning technologists and tutors as an effective driver which acts 'horizontally' with respect to other tutors.

\section{Coordinated dissemination of CAA practice}

One aspect of the model that hinged on mediated support from learning technologists was achieving a 'critical mass' of CAA use. Learning technologists in centralised institutions have a strategic role which permits them to coordinate update by controlling uptake directly from the top down: 


\section{Coordinated procedural risk mitigation}

In some more centralised universities procedural risk mitigation enforces lower risk practice through institutional fiat:

\section{Coordinated physical risk mitigation by central L\&T specialists}

Tutors and learning technologists who had experience of high stakes CAA testing were keen to reduce the chance of something going wrong at a critical time by having institutions invest in suitable physical infrastructures.

\section{Coordinated strategy for CAA uptake approved by senior management}

Having a member of senior management as an advocate for CAA was cited as crucial by experienced learning technologists. Efforts to develop integrated managed learning environments (MLEs) at a strategic level were identified as both an obstacle where absent and a driver where present. The relationship between the uptake of VLEs and of CAA uptake was described as one where neither could advance more than one step beyond the other. Tutors have to make their own logistical arrangements for high-stakes summative tests when institutions do not support CAA examinations via the Examinations Office. This presents an effective obstacle to uptake.

\section{Coordinated resourcing provided through senior management}

There was clear agreement from learning technologists and tutors about the central importance of centralised support and resourcing:

... when I was at Havenpool, it sort of failed simply because the central services didn't take it on... something about the way it was done without a central team... So there was no central agreement and no institutional drive, so it didn't work, no-one really was sure of who's doing what and why were they doing it anyway, you know? ... you need [the institution] to build a solid foundation... (Learning technologist LtN4FO01)

\section{External influences}

Central government funding initiatives may drive uptake by providing an incentive for institutions to implement centralised CAA systems. The pressure from the quality assurance agency (QAA) for more frequent formative feedback should not be underestimated as a driver for uptake at the level of individual tutors:

... there is an awful lot of pressure on teachers ... to provide feedback to students... And that's where...[CAA]... is a scalable method of giving feedback to students as they progress through... the QAA are kind of very heavy about [formative feedback] at the moment... the students... go through the semester, they get a semester exam and there's nothing that...could have ever told them how they were doing. (Tutor AmO4M017) 


\section{Principle Mechanisms Inhibiting CAA Uptake}

The principle mechanisms that emerged from the questionnaire returns and the interviews as inhibiting the uptake of CAA in UK universities were also sevenfold and are described in ascending order of scale. They are depicted below using the concentric cylinder model of uptake (Figure 6).

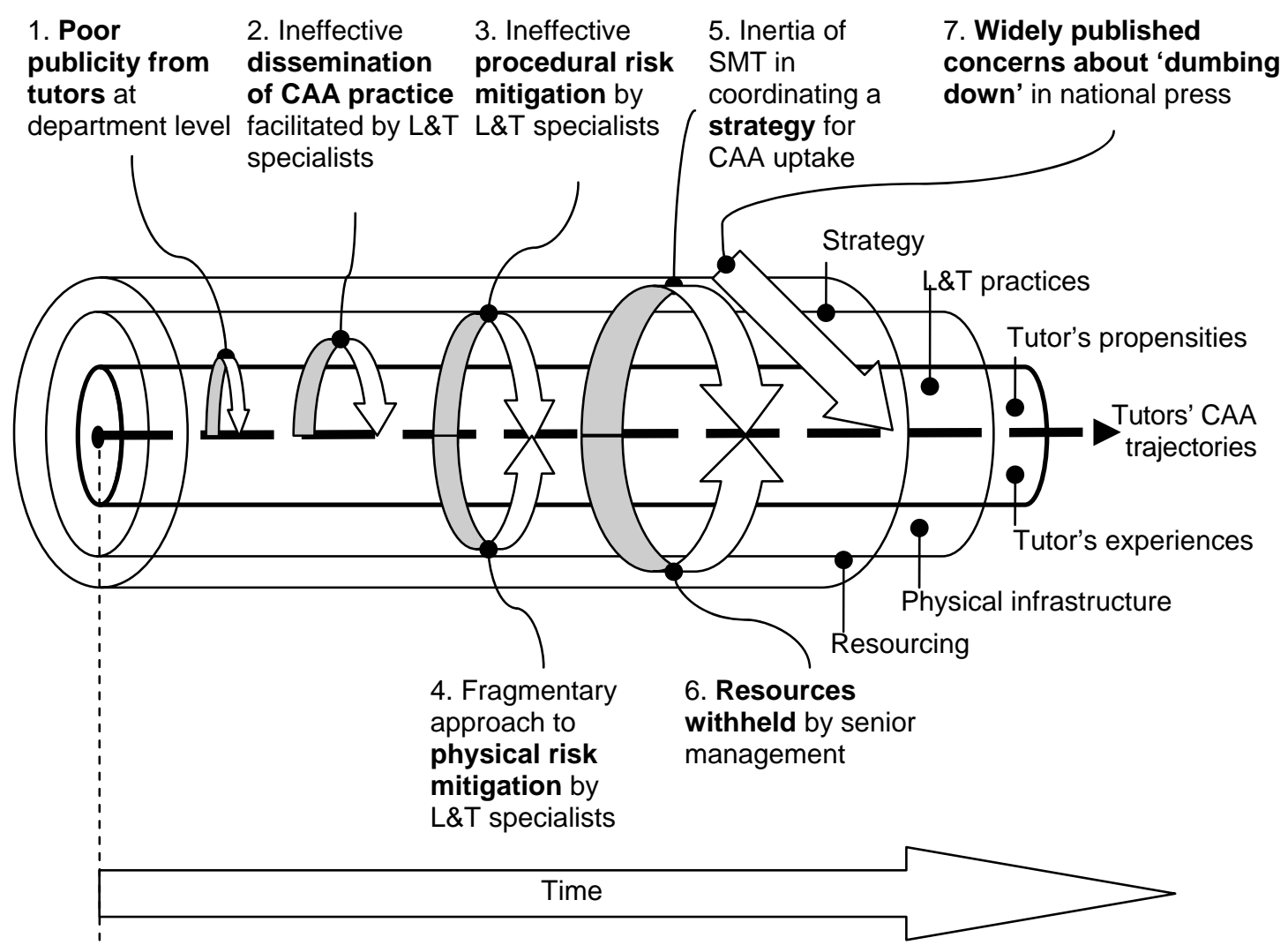

Figure 6- Concentric cylinder model of principle mechanisms inhibiting CAA uptake

\section{CAA failures of invigilated tests and fear of these}

CAA failures, especially in high stakes invigilated summative tests, have serious consequences for uptake at every level. The consequences are most severe for the tutor because students feel they are under enough pressure without assessment glitches to make things worse. Fears of embarrassment about high-stakes failures resulted in 'confidentiality bubbles' (Harwood, 2002) that restrict diffusion of these events beyond the boundaries of individual academic departments or groups of learning technologists. The basis of this embarrassment appeared to be a perceived threat to the credibility of tutors and departments:

... [we thought] they'd tell us it was our own fault or something... there's that nagging feeling you get that you forgot to do something vital, like did you turn off the gas? (Tutor AsO4F003)

This under-reporting of CAA failures contributed to a widespread perception that high-stakes CAA tests were less risky than they really were, which acted 
as a driver for uptake particularly among tutors who have naïve understandings of technology:

I think its more of a problem with the staff is their tendency to overestimate their ability to use computers... They think maybe because they can use a wizard in POSH-CAA, that... they're an author for CAA... (Learning technologist LtO3M004)

\section{Ineffective dissemination of good CAA practice}

CAA uptake is vulnerable to attacks from vociferous critics who may have their own agendas based on perceived threats to a department's credibility:

There's probably a few people [here] who'd love to see one go wrong so they could avoid it, I think and never touch the system again. It's a bit Machiavelli. (Tutor AsO3M002)

The 'quick win' attitude towards CAA is clearly recognisable as a brake on uptake through external examiners' reports to departments:

[external examiners] realise that there are good ways of using it... but there are other staff who see it as a timesaver and therefore do not put as much time into question development and management as could be put in, therefore tests are not as academically testing as could be - so [external examiners] are not as happy... (Tutor AmN3F001)

\section{Ineffective procedural risk mitigation}

Procedures which do not yet exist, or which are difficult to interpret, constitute an effective obstacle to uptake. Failures to comply with known procedures can have devastating effects on CAA uptake:

...we had an incident this year where one of the lecturers ...neglected a procedure which compromised the exam just beforehand and now they have gone off using the system as a result of that oversight. So even though the procedures were in place and he neglected to do one aspect, it has tarnished [their] view on [CAA]... (Learning technologist LtN2M003)

\section{Fragmented approach to physical risk mitigation}

CAA systems which are not made easy to use are regarded by both tutors and learning technologists as a significant obstacle to uptake:

And I do think you are totally right about the infrastructure and operational conditions and one of the things l've introduced... - well it would take maybe 10 minutes if you were really slick... and in that 10 minutes you could have covered a chapter in the syllabus. So only the really keen ones did it. So I think the infrastructure, yes, is a crucial thing there. Yes, ease of use, that's right, exactly - it is, yes. (Learning technologist Am05M007) 
The difficulty of load-testing CAA systems emerged as a significant obstacle to uptake.

\section{Institutional strategy shortfall}

The inertia associated with institutions approving CAA applications acts as a brake on innovation by leaving little time for busy tutors to change their practice. As a complement to institutional inertia, one learning technologist cited ongoing organisational change as being itself an obstacle to innovation in assessment:

And it's exactly an inertia of change which is a ridiculous thing to say, but because we're changing we can't do a lot of things. (Learning technologist LtO5M006)

Learning technologists identified failure to implement an overarching strategy at the institutional level as a significant brake on uptake because those wishing to use CAA in summative applications are often obliged to wait for institutions to give permission.

\section{Resources withheld by senior management}

According to learning technologists, the pace of organisational change was sometimes cited by senior management as a good reason for not investing in institutional CAA infrastructure such as large workstation areas:

What you're talking about is not investing a lot of money in a large, or several large 200-seat computer clusters. I have a sneaking suspicion here that the actual driver behind this is that the University doesn't like spending money. (Learning technologist LtO5M006)

A reluctance on the part of senior management to invest in infrastructure until uptake had increased to the point where it was justified was said to compound the lack of suitable workstation areas as a brake on uptake:

... I've been told that we won't get infrastructure unless we can demonstrate there's a demand. The problem is you can't stimulate the demand unless you can demonstrate there's an infrastructure in which it can work. So its one of these sorts of circular arguments, where it's very difficult to know how it's going to be taken forward. (Learning technologist LtO5M006)

\section{Widespread concerns about 'dumbing down'}

Fears of 'dumbing down' inhibit uptake by affecting the perceptions of external stakeholders such as employers regarding the use of CAA in HE. This may have discouraged some departments from using CAA:

... external factors... may have a knock on effect for the university if it is using CAA if there a perception by the employers that it's no good and they won't employ people because of this then they might stop using it and switch to more traditional assessment methods. (Learning technologist LtN2M003) 


\section{Applications of Dual-path Theory}

Three models describing different aspects of uptake emerged from the central dual-path theory. These were the trajectory, concentric shell and concentric cylinder models which could be used both to identify weaknesses in HE institutional practice and to suggest where resources should best be targeted to strengthen uptake. For example, an institutional survey of CAA users and non-users could furnish a register of site-specific obstacles and drivers to populate the concentric shell template. This would illustrate the local balance of existing good CAA practice compared with applications might benefit from mediation. The impact of cumulative institutional hysteresis would be shown by populating a concentric cylinder template with local equivalents of known factors such as an incoherent learning and teaching strategy.

\section{The Contended Notion of 'Successful' Uptake}

The uptake of CAA must be considered in the context of 'successful' practice. If a consensus exists that practice across an institution is optimal then there is little incentive to take corrective action. However, stakeholders were found to take different views of this according to their position within the institution. For example, tutors tended to concentrate on completing assessments tasks with maximal efficiency (and minimal student unrest) whilst learning technologists were interested in pedagogic fitness for purpose and extending technical boundaries. The importance of scale emerged as another contentious aspect of uptake (Figure 7).

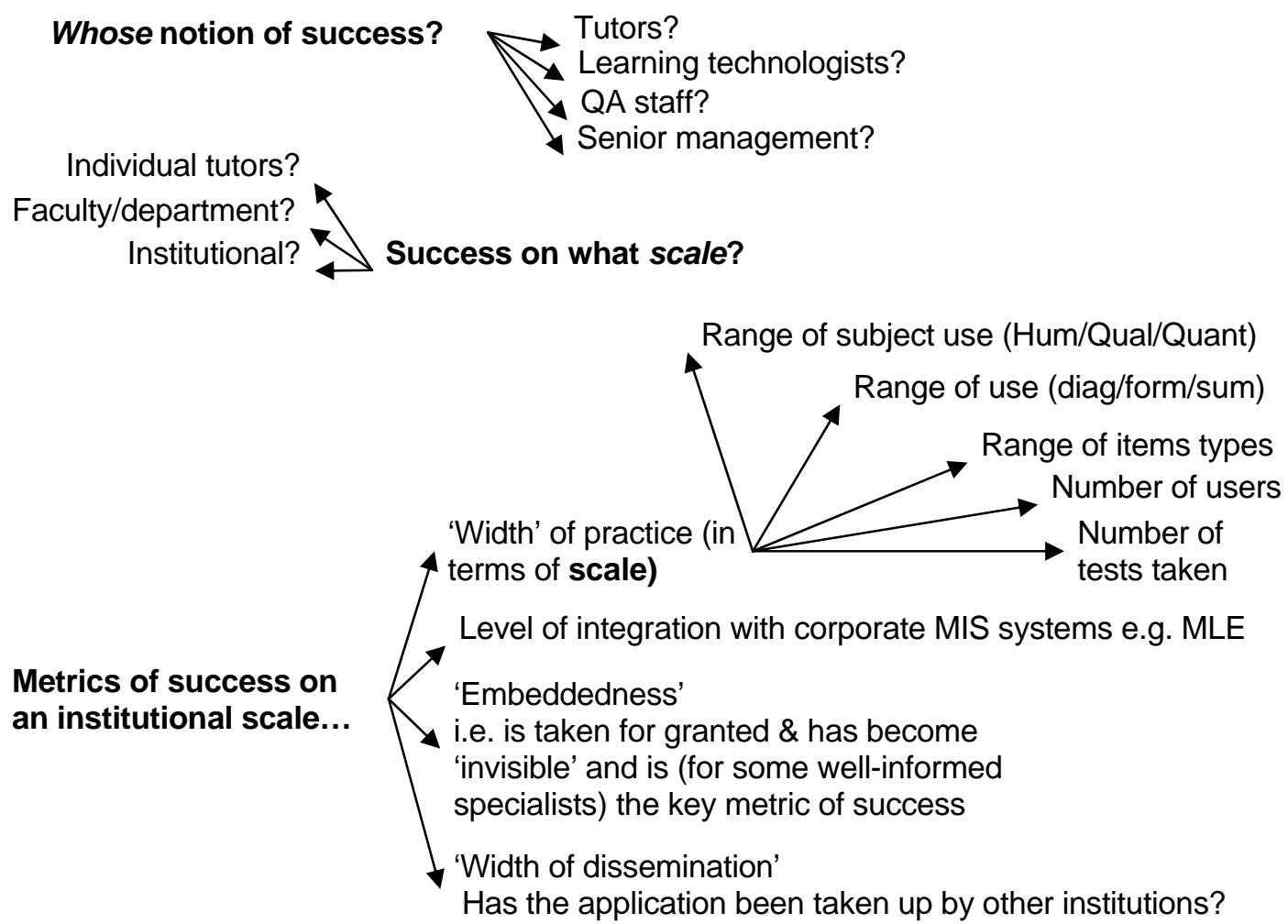

Figure 7- metrics for successful implementation 


\section{Discussion}

At the level of individual tutors, risk propensity appears to be a good predictor of CAA trajectory type and could be used to direct support resources where they might be used most effectively to mitigate risky practice. Trajectories seem to be good descriptors of CAA uptake patterns and provide an effective and concise way of characterising existing and future practice. Metrics for 'good' CAA practice are admittedly contentious but efforts must be made to establish reference points which are recognisably grounded in wider communities of practice. The crude distinction drawn here between the 'quick win' and 'slow burn' patterns of uptake could be taken as the simplest possible way of differentiating different patterns of CAA practice. It might be argued that a lack of clear descriptors has until now contributed to the difficulty of agreeing common reference points for characterising uptake.

This paper described the development of a grounded theory of CAA uptake in UK HE institutions, known as the 'dual-path' theory. Three models developed from this theory can be used to understand CAA practice at the levels of individual tutors, infrastructure and entire institutions. These models can be used to identify weaknesses in HE institutional practice and to suggest where resources might be committed to optimise uptake. Notions of 'successful' uptake are contentious due to differences in stakeholder perspective. 


\section{References}

HARWOOD, I. (2002) Developing Scenarios for Post-Merger and Acquisition Integration: A Grounded Theory of Risk Bartering. Unpublished PhD thesis, University of Southampton.

HARWOOD, I. \& WARBURTON, W. (2004) Thinking the Unthinkable: Using Project Risk Management when Introducing Computer-assisted Assessments. IN: DANSON, M., ed., Proceedings of 8th International CAA Conference. Loughborough, University of Loughborough.

WARBURTON, W. \& CONOLE, G. (2005) Wither e-Assessment? IN: DANSON, M., ed., Proceedings of 9th International CAA Conference. Loughborough, University of Loughborough. 